\title{
SUSCETIBILIDADE À EROSÃO HÍDRICA NA BACIA HIDROGRÁFICA DO RIO PAJEÚ, PERNAMBUCO
}

\author{
Elvis Bergue Mariz Moreira ${ }^{(a)}$, Deivide Benicio Soares ${ }^{(b)}$, Eberson Pessoa Ribeiro ${ }^{(\mathrm{c})}$, Ranyére \\ Silva Nóbrega ${ }^{(\mathrm{d})}$
}

(a) Doutor em Geografia, Prof. da Universidade Federal do Oeste da Bahia UFOB, Centro das Humanidades, Curso

de Geografia, elvis.moreira@ufob.edu.br

(b) Doutor em Geografia, Grupo de Estudos em Climatologia Tropical e Eventos Extremos (Tropoclima)/UFPE, deividebenicio@yahoo.com.br

(c) Doutor em Geografia, Prof. do Instituto Federal de Pernambuco, Campus Vitória de Santo Antão, eberson.pessoa@vitoria.com.br

(d) Doutor em Meteorologia, Prof. da Universidade Federal de Pernambuco, Departamento de Ciências Geográficas, raniere.nobrega@ufpe.br

\section{Eixo: GEOGRAFIA FÍSICA E DESASTRES NATURAIS}

\begin{abstract}
Resumo
O presente trabalho tem por objetivo estimar a perda de solo anual por erosão hídrica na bacia hidrográfica do Rio Pajeú, a maior bacia hidrográfica do estado de Pernambuco, totalmente inserida na região semiárida, suscetível à desertificação. $\mathrm{O}$ cálculo da equação universal de perda de solo revisada foi realizado através do modelo InVEST SDR (versão 3.2.0), o qual estima a perda anual de solo para cada pixel do terreno. Foi estimada uma perda média de solo por erosão hídrica entre $0,2 \mathrm{e}$ $2,5 \mathrm{t} / \mathrm{ha} /$ ano para os diferentes municípios da bacia. A perda média estimada para o conjunto das terras da bacia hidrográfica do Rio Pajeú foi de 0,97 t/ha/ano, o que se traduz em uma suscetibilidade de perda anual de 1.644.261 toneladas de solo por erosão hídrica na bacia.
\end{abstract}

Palavras chave: erosividade, erodibilidade, RUSLE, semiárido, desertificação.

\section{Introdução}

O depauperamento do solo é uma preocupação constante de vários setores da sociedade, principalmente de ambientalistas, pois é relativamente fácil de perceber os sinais que revelam esse desgaste, mas é difícil prever quais serão as más consequências futuras (LEPSCH, 2002), uma vez que a aceleração do ritmo de erosão produz condições anormais, como perda da produção agrícola, redução das taxas de aporte e decomposição da matéria orgânica, ravinamento, entre outros. A degradação do solo se configura com uma das mais graves problemáticas ambientais, visto que o solo é considerado como um recurso finito, não renovável na escala de duração da vida humana.

As principais causas do empobrecimento dos solos das terras agrícolas são por meio de processos erosivos. A erosão é um processo que pode ser definido como a desagregação, o transporte e a deposição do solo, subsolo e rochas em decomposição (GALETI, 1982), podendo ser geológica (natural) ou 


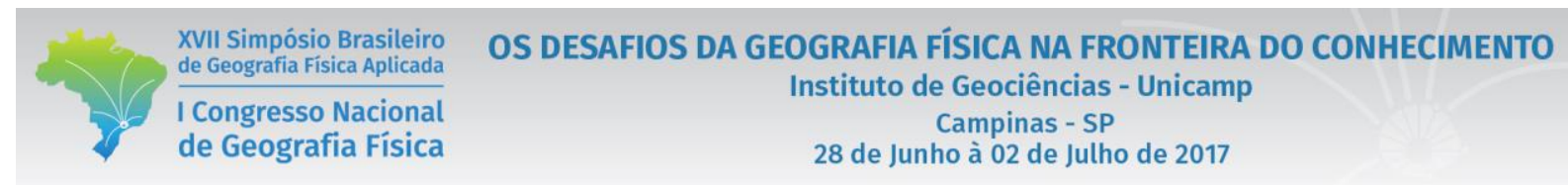

acelerada (antrópica). De acordo com Guerra e Guerra (2003), a erosão geológica é realizada normalmente pelos diversos agentes erosivos sem que haja a intervenção do homem, acelerando o trabalho de destruição e construção feito por estes agentes. Quando se verifica a intervenção do homem, acarretando desequilíbrios que favorecem o trabalho da erosão, temos a chamada erosão acelerada.

Nas regiões semiáridas, a perda de solo por erosão pode ser considerada, ao mesmo tempo, causa e efeito do processo de desrtificação. Conforme aponta Abraham (2006), a erosão hídrica representa um dos indicadores de desertificação consensuados por pesquisadores dos países participantes do Programa de Luta Contra a Desertificação e Mitigação dos Efeitos da Seca na América do Sul.

Nesse contexto, o presente trabalho tem por objetivo estimar a perda de solo anual por erosão hídrica na bacia hidrográfica do Rio Pajeú, a maior bacia hidrográfica do estado de Pernambuco, totalmente inserida na região semiárida, suscetível à desertificação.

\section{Materiais e métodos}

A bacia hidrográfica do Rio Pajeú (Figura 1) é a maior bacia de Pernambuco, com uma área de 16.838,70km2, que corresponde a 17,02\% da área do Estado (PERNAMBUCO, 1998). Está localizada, em sua totalidade, em Pernambuco, formando a Unidade de Planejamento Hídrico UP9, entre 76'20" e $8^{\circ} 56^{\prime} 01^{\prime \prime}$ de latitude sul, e $36^{\circ} 59^{\prime} 00^{\prime \prime}$ e $38^{\circ} 57^{\prime} 45^{\prime \prime}$ de longitude a oeste de Greenwich.

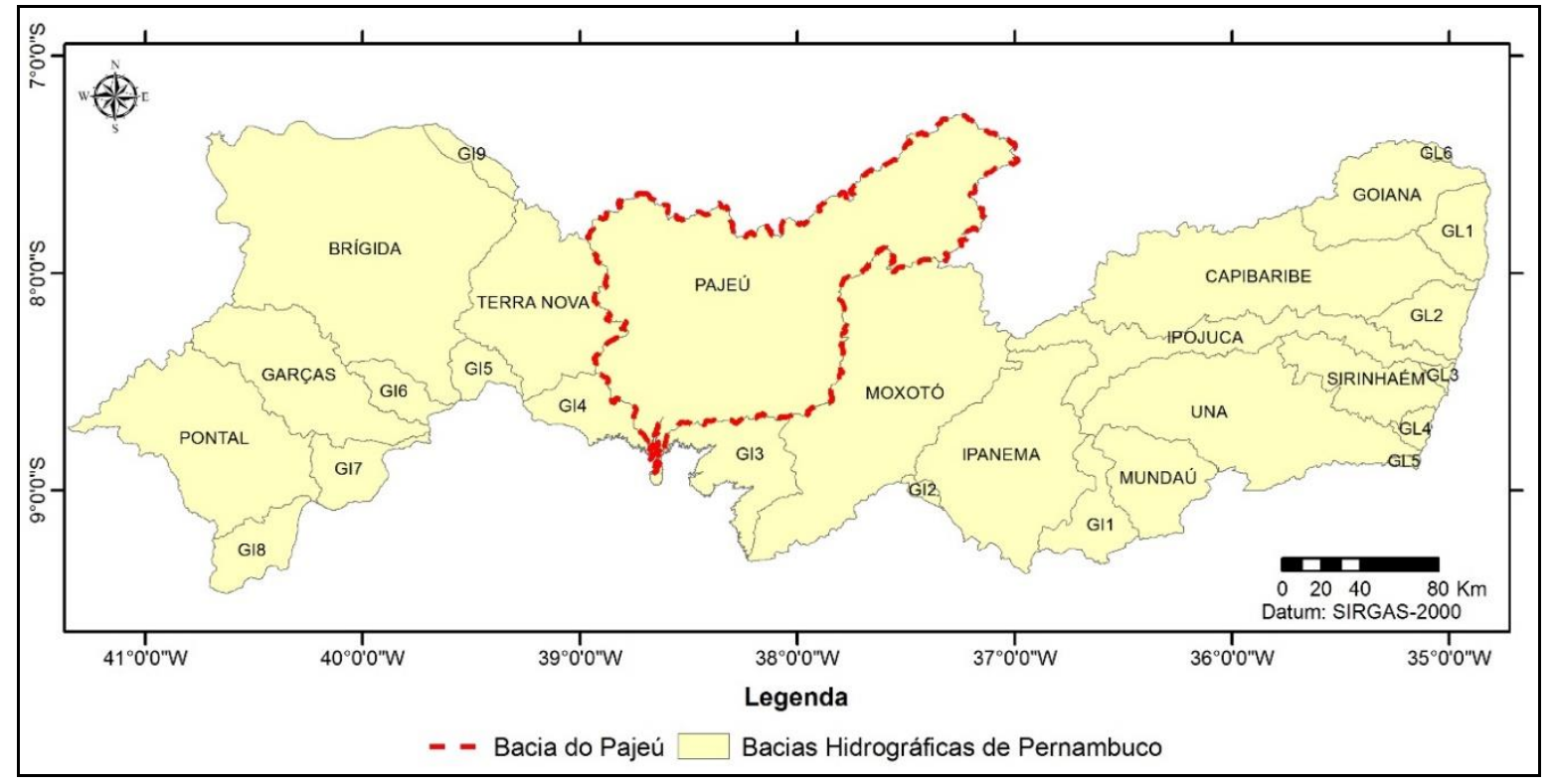

Figura 1 - Localização da área de estudo 
A avaliação de perdas de solo por meio de equações empíricas tem se tornado uma prática comum e indispensável para o planejamento de práticas conservacionistas em áreas cultivadas. As técnicas de estimativas de perdas de solo vêm sendo aprimoradas proporcionando segurança nas estimativas, além de serem empregadas em escala universal por meio da obtenção de informações específicas das localidades. Dessa forma, essas equações visam o planejamento do uso do solo e determinação de práticas de conservação mais adequadas para uma dada área (BERTONI; LOMBARDI NETO, 2012).

A Equação Universal da Perda de Solo (EUPS) / Universal Soil Loss Equation (USLE), desenvolvida por Wischmeier e Smith (1978), é algoritmo mais comum no estudo da erosão e na estimativa das perdas de solo. Esse modelo foi revisado por Renard et al. (1997) passando a ser designada como Revised Universal Soil Loss Equation (RUSLE). A RUSLE estima a erosão do solo e serve de guia sistemático no planejamento da conservação do solo através dos principais fatores que influenciam a erosão.

A RUSLE é expressa por:

\section{$\boldsymbol{A}=\boldsymbol{R} \cdot \boldsymbol{K} . \boldsymbol{L S} \cdot \boldsymbol{C} \cdot \boldsymbol{P}$}

Onde,

- A é a perda média anual de solo em tonelada por hectare por ano (t/ha/ano);

- R é o fator de erosividade da chuva, expresso em Megajoule por milímetro por hectare por hora por ano (MJ.mm/ha.h.ano);

- K é o fator erodibilidade do solo, expresso em t.ha.h/ha.MJ.mm;

- LS é o fator topográfico, adimensional;

- C é o fator de uso e cobertura do solo, adimensional;

- P é o fator de práticas conservacionistas, adimencional.

Diversos trabalhos no Brasil e no mundo (ADEDIJI; TUKUR; ADEPOJU, 2010; PULIDO GÓMEZ, 2012; FARHAN; ZREGAT; FARHAN, 2013; MARQUES, 2013) apontam que a RUSLE é um instrumento precioso para a conservação dos solos devido a sua precisão nas estimativas de perdas médias anuais de solo sob determinadas condições ecológicas (R, K, L e S) e fatores antrópicos (C e P).

O cálculo da perda de solo por erosão hídrica (RUSLE) da bacia do Pajeú foi realizado através do modelo InVEST SDR (versão 3.2.0), baixado, gratuitamente, em novembro de 2015, na página do "Projeto Capital Natural" (http://www.naturalcapitalproject.org).

O SDR (Sediment Delivery Ratio model), Modelo de Exportação de Sedimentos, é um dos modelos da plataforma InVEST (Integrated Valuation of Environmental Services and Tradeoffs) - que traduzido para o português seria Avaliação Integrada de Serviços Ambientais e Compensações - desenvolvida pelo 


\section{OS DESAFIOS DA GEOGRAFIA FÍSICA NA FRONTEIRA DO CONHECIMENTO \\ Instituto de Geociências - Unicamp \\ Campinas - SP \\ 28 de Junho à 02 de Julho de 2017}

Natural Capital Project, da Universidade de Stanford, na Califórnia (USA), em parceria com o Institute on the Environment, da Universidade de Minessota (USA), The Natura Conservancy (TNC) e World Wildlife Fund (WWF).

De acordo com Sharp et. al. (2015), o InVEST tem como objetivo apoiar a tomada de decisão na gestão dos recursos naturais, fornecendo informações sobre alterações nos ecossistemas, na tentativa de evitar prejuízos ao bem-estar da população. Possui um conjunto de ferramentas de modelagem matemática voltadas ao mapeamento, quantificação e valoração econômica de serviços ambientais, constituído por 20 módulos, dentre eles, o de exportação de sedimentos (SDR).

O uso do modelo InVEST SDR dispensa softwares de geoprocessamento, sendo aberto diretamente através do gerenciador de aplicativos do computador. Seus dados de saída, porém, podem ser acessados em ambiente SIG, tendo sido utilizado o ArcGIS 10.3 (versão demonstrativa).

No modelo InVEST SDR a perda anual de solo é calculada para cada pixel do terreno, sendo determinada pela equação universal de perda de solo revisada. Os dados de entrada requeridos pelo modelo são:

- Limite da bacia hidrográfica (arquivo shapefile no formato de polígono);

- Limite das sub-bacias (arquivo shapefile no formato de polígono);

- Mapa de erosividade (arquivo raster);

- Mapa de erodibilidade (arquivo raster);

- Modelo Digital de Elevação (MDE) (arquivo raster);

- Mapa de uso e cobertura do solo (arquivo raster);

- Tabela "biofísica", com os valores dos fatores C e P (arquivo .csv);

- Parâmetros adicionais.

O limite da bacia hidrográfica do rio Pajeú foi obtido a partir do mapa das bacias hidrográficas / unidades de planejamento hídrico do Estado de Pernambuco (PERNAMBUCO, 2006), cuja base cartográfica foi cedida pela Agência Pernambucana de Águas e Clima (APAC).

Para obtenção do índice de erosividade das chuvas (fator R) foram utilizadas as médias históricas de precipitação de 98 estações pluviométricas distribuídas por todo o Estado de Pernambuco, cedidas pela APAC. O cálculo do fator $\mathrm{R}$ foi realizado a partir da equação proposta por LOMBARDI NETO e MOLDENHAUER (1992) expressa por:

$$
E I=68,730\left(\frac{p^{2}}{P}\right)^{0,841}
$$


Onde, "EI" é a média mensal do índice de erosão em MJ.mm/ha.h.ano, "p" é a precipitação média mensal em milímetros e "P" é a precipitação média anual em milímetros.

O índice de erosão médio anual, isto é, o fator $\mathrm{R}$ para um local, é a soma dos valores mensais do índice de erosão. Assim, utilizou-se a Equação 04 para calcular o índice de erosividade de cada mês, e a soma dos valores obtidos ao longo do ano constituiu o índice médio anual de cada uma das estações pluviométricas. Depois disso, foi feita a interpolação dos valores do índice de erosividade médio anual para todo o Estado de Pernambuco através do método do inverso do quadrado da distância (IDW) no ArcGIS 10.3. O mapa de erosividade (arquivo raster) da bacia do Pajeú foi obtido, então, mediante a técnica de "extração por máscara" no ArcGIS 10.3, com o recorte da bacia do Pajeú no mapa de erosividade de Pernambuco.

O fator erodibilidade dos solos $(\mathrm{K})$ foi calculado pelo método indireto, através da equação proposta por Bouyoucos (1935), citada por Hudson (1982) e Bertoni e Lombardi Neto (2012) e utilizada por Mannigel (2002) e Castro et al. (2011):

\section{Fator $\boldsymbol{K}=((\%$ areia $+\%$ silte $) / \%$ argila $) / 100$}

Aplicou-se a referida equação para os diferentes horizontes dos solos existentes na área de estudo, sendo o fator $\mathrm{K}$ de cada classe de solo a média aritmética dos valores aferidos para seus sub-horizontes.

Os percentuais de areia, silte e argila foram obtidos a partir das descrições dos perfis de solo disponíveis na página da internet do "Sistema de Informações de Solos Brasileiros" (EMBRAPA, 2015). Foram utilizadas como parâmetro as descrições dos perfis de solos do semiárido pernambucano, visto que uma mesma classe de solo pode apresentar textura diferente em condições climáticas diferentes.

O fator topográfico é calculado automaticamente no modelo InVEST, sendo necessário, apenas, adicionar um modelo digital de elevação (MDE) da área de estudo, um arquivo em formato raster que contém informações altimétricas em cada célula/pixel.

O MDE da bacia do Pajeú foi criado a partir das imagens SRTM (Shuttle Radar Topography Mission), disponíveis na página do projeto "Brasil em Relevo" (MIRANDA, 2005).

Para cobrir toda a extensão da bacia do Pajeú foram necessárias as imagens SRTM das folhas SB-24-Z-C, SB-24-Z-D e SC-24-X-A (escala 1250.000). As três folhas foram unidas através do procedimento "mosaic to new raster" no ArcGIS 10.3 e, posteriormente, foi feito o recorte da bacia do Pajeú mediante o procedimento "extract by mask".

Na elaboração da tabela biofísica foram utilizados os parâmetros oferecidos pelo próprio modelo para as categorias: uso agropecuário, cobertura urbana e corpos hídricos, vegetação densa e vegetação aberta. 
Estas categorias de uso foram identificadas a partir do Sistema de Informações Geográficas do Programa de Monitoramento do Desmatamento nos Biomas Brasileiros por Satélite (PROBIO) - bioma caatinga disponibilizados na página da internet do Ministério do Meio Ambiente do Brasil.

\section{Resultados e discussões}

A espacialização da erosividade das chuvas na bacia do Pajeú seguiu, como esperado, comportamento semelhante à distribuição da pluviometria na bacia, ou seja, na fachada norte, onde chove mais, foram registrados os maiores valores de erosividade, com destaque para a região de Triunfo, onde a erosividade chegou a 6.057 MJ.mm/ha.h.ano. Os valores de erosividade vão decrescendo em direção ao sul da bacia, atingindo o mínimo de 3.275 MJ.mm/ha.h.ano no entorno do núcleo urbano de Betânia, Floresta e Itacuruba, conforme se pode observar na Figura 2.

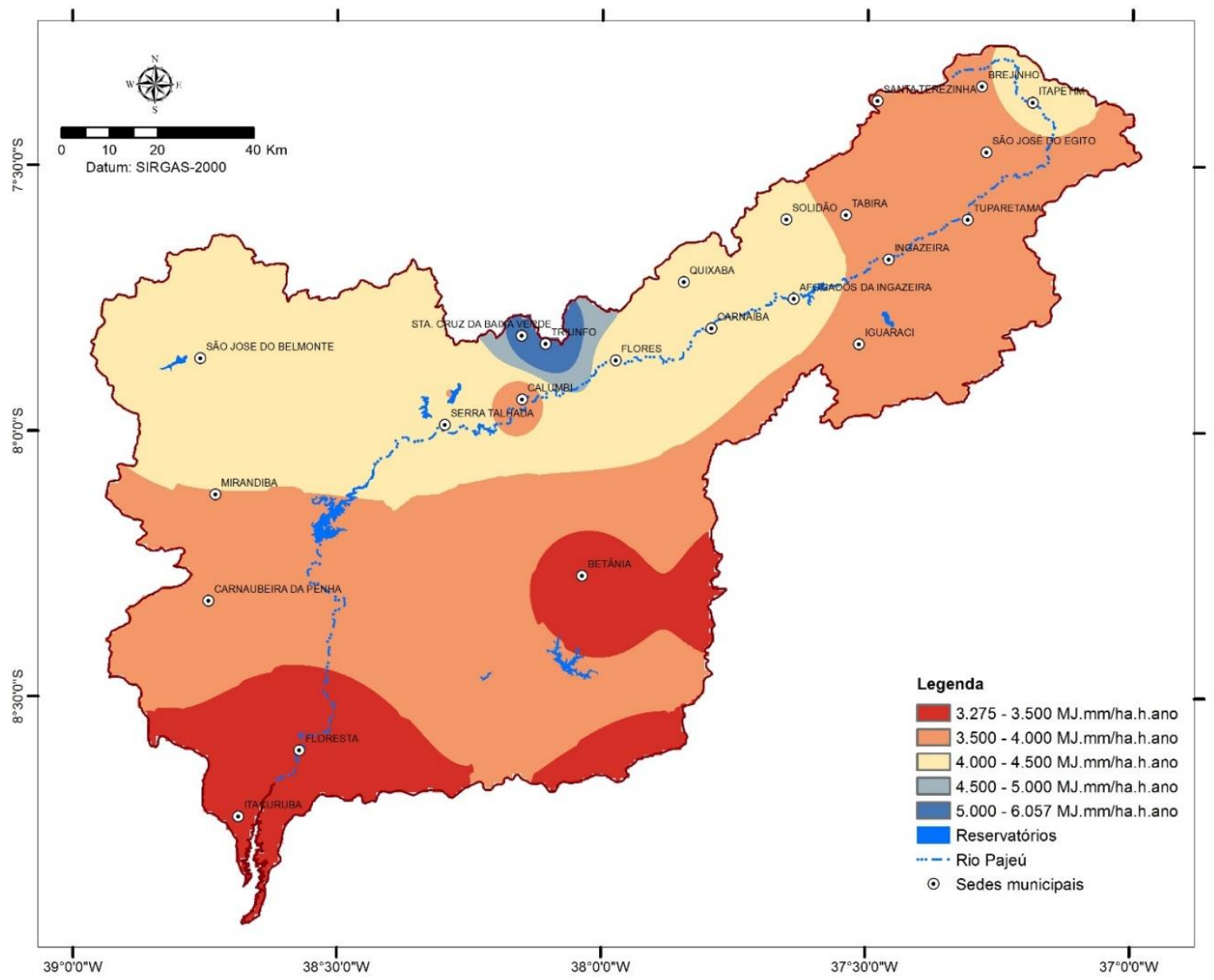

Figura 2 - Erosividade das chuvas na bacia do Pajeú 


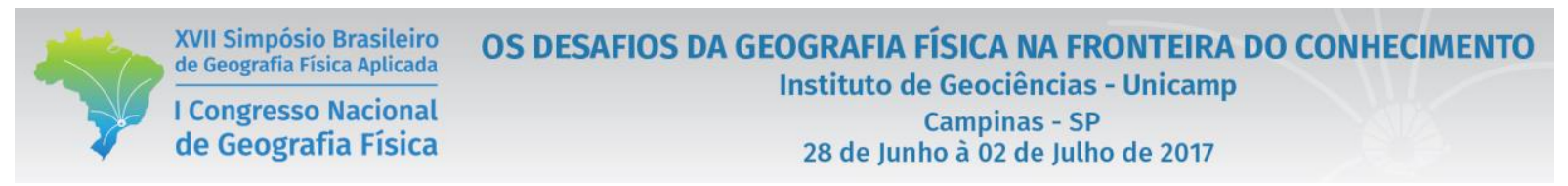

A erodibilidade dos solos se mostrou mais elevada em solos de textura arenosa, geralmente associados a terrenos sedimentares, com destaque para a área do distrito de São Caetano do Navio, a nordeste da sede urbana do município de Betânia; as regiões dos distritos de Sítio dos Nunes e Fátima, ao sul da sede urbana do município de Flores; no município de Santa Terezinha, no alto Pajeú; além de trechos isolados dos municípios de Carnaubeira da Penha, Floresta e Serra Talhada, que apresentaram erodibilidade acima de 0,3 t.ha.h/ha.MJ.mm, conforme se pode observar na Figura 3. Também apresentaram elevada erodibilidade os solos do município de São José do Belmonte, Mirandiba e um extenso trecho que recobre os distritos de Caiçarinha da Penha e Tauapiranga, pertencentes ao município de Serra Talhada, cuja erodibilidade é estimada entre 0,2 e 0,3 t.ha.h/ha.MJ.mm.

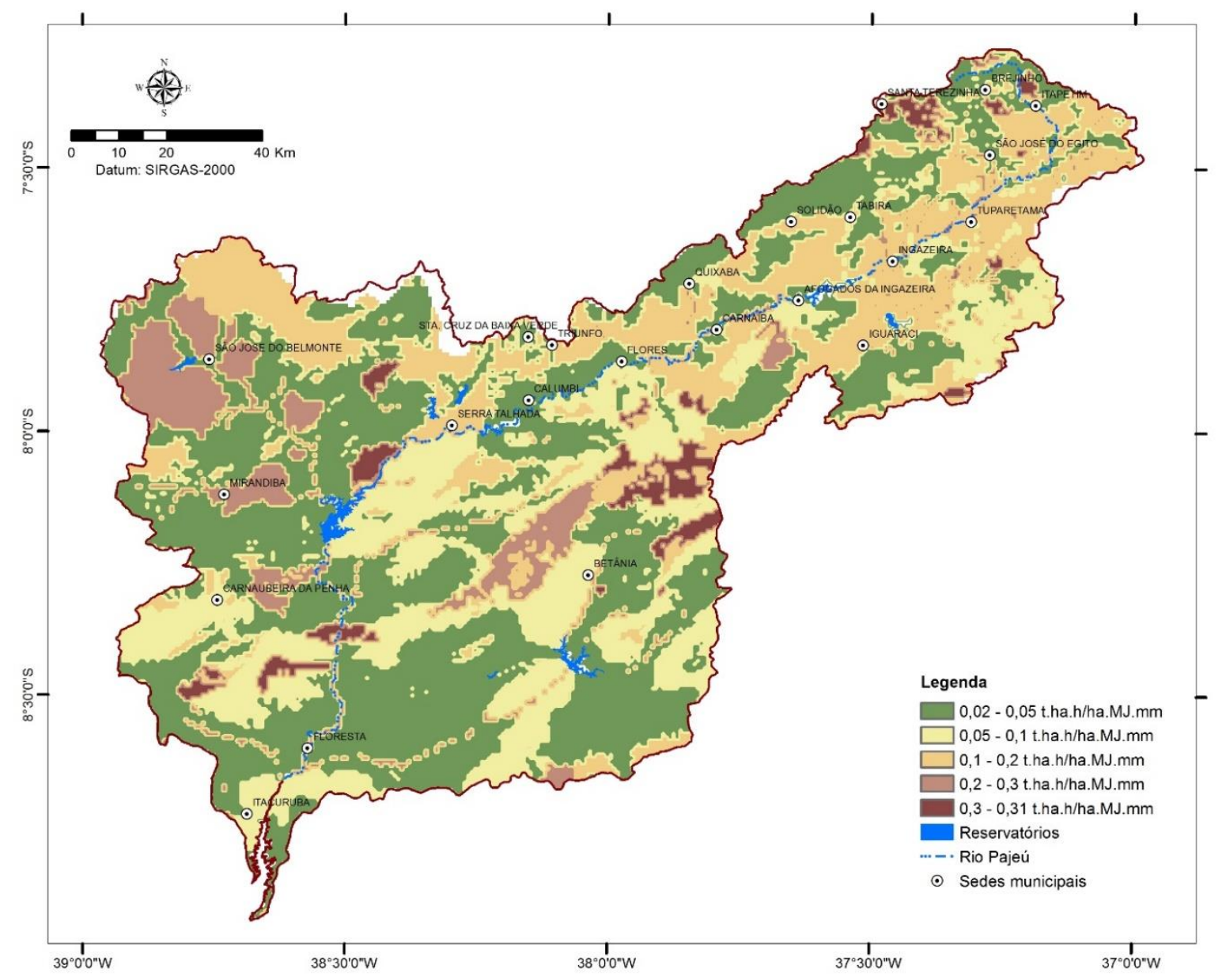

Figura 3 - Erodibilidade dos solos na bacia do Pajeú

O fator LS, associado à declividade de rampa, se mostrou mais elevado no entorno das regiões serranas, como na fachada norte da bacia, desde o município de Serra Talhada até o município de Solidão, com 


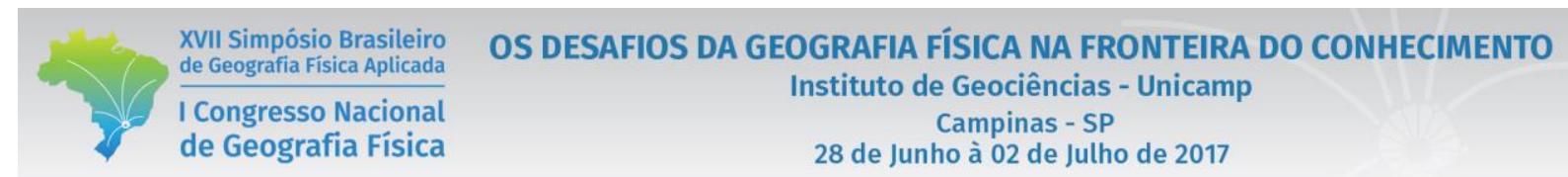

destaque para a região da Serra da Baixa Verde, nos municípios de Triunfo e Santa Cruz da Baixa Verde, e nas serras dos arredores da área urbana de Carnaubeira da Penha, bem como no entorno de outros Granitoides e Inselbergues isolados, como se pode observar na Figura 4.

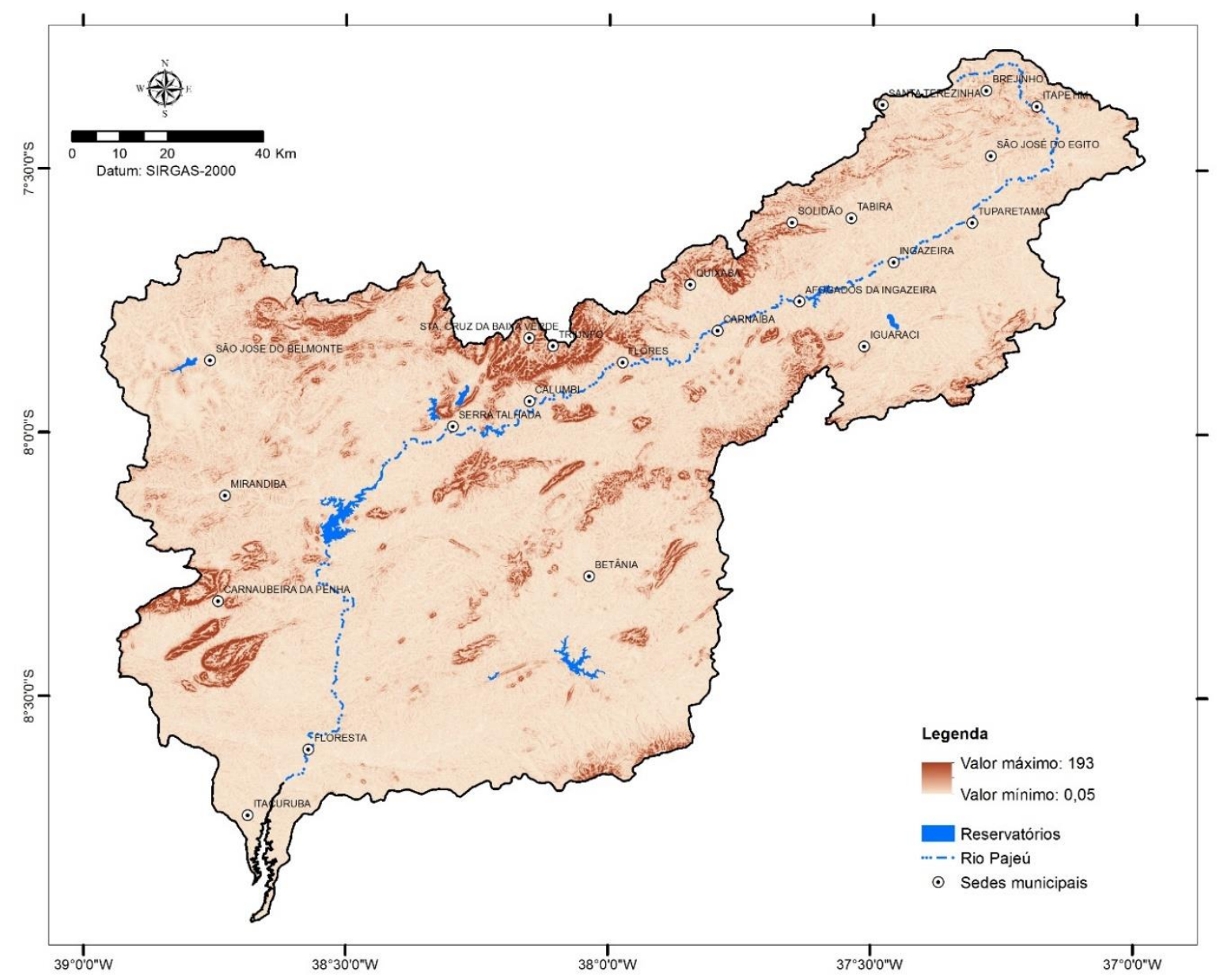

Figura 4 - Fator LS calculado para a bacia do Pajeú

Após computar os resultados da erosividade das chuvas, erodibilidade dos solos, declividade de rampa junto com os fatores $\mathrm{C}$ e P que estão relacionados com o uso e cobertura do solo, o modelo InVEST SDR gerou a estimativa da perda de solo anual por erosão hídrica para cada município da bacia do Pajeú, cujos valores variaram de 0,2 a 2,5 t/ha/ano, conforme se pode observar na Figura 5.

Os municípios que apresentaram maior média de perda de solo anual por erosão hídrica na bacia do Pajeú foram Carnaubeira da Penha (2,48 t/ha/ano), Calumbi (2,33 t/ha/ano) e Carnaíba (1,60 t/ha/ano), e os menores valores foram observados em Itacuruba (0,21 t/ha/ano), na foz, e em Brejinho (0,37 t/ha/ano) na cabeceira do rio Pajeú. 


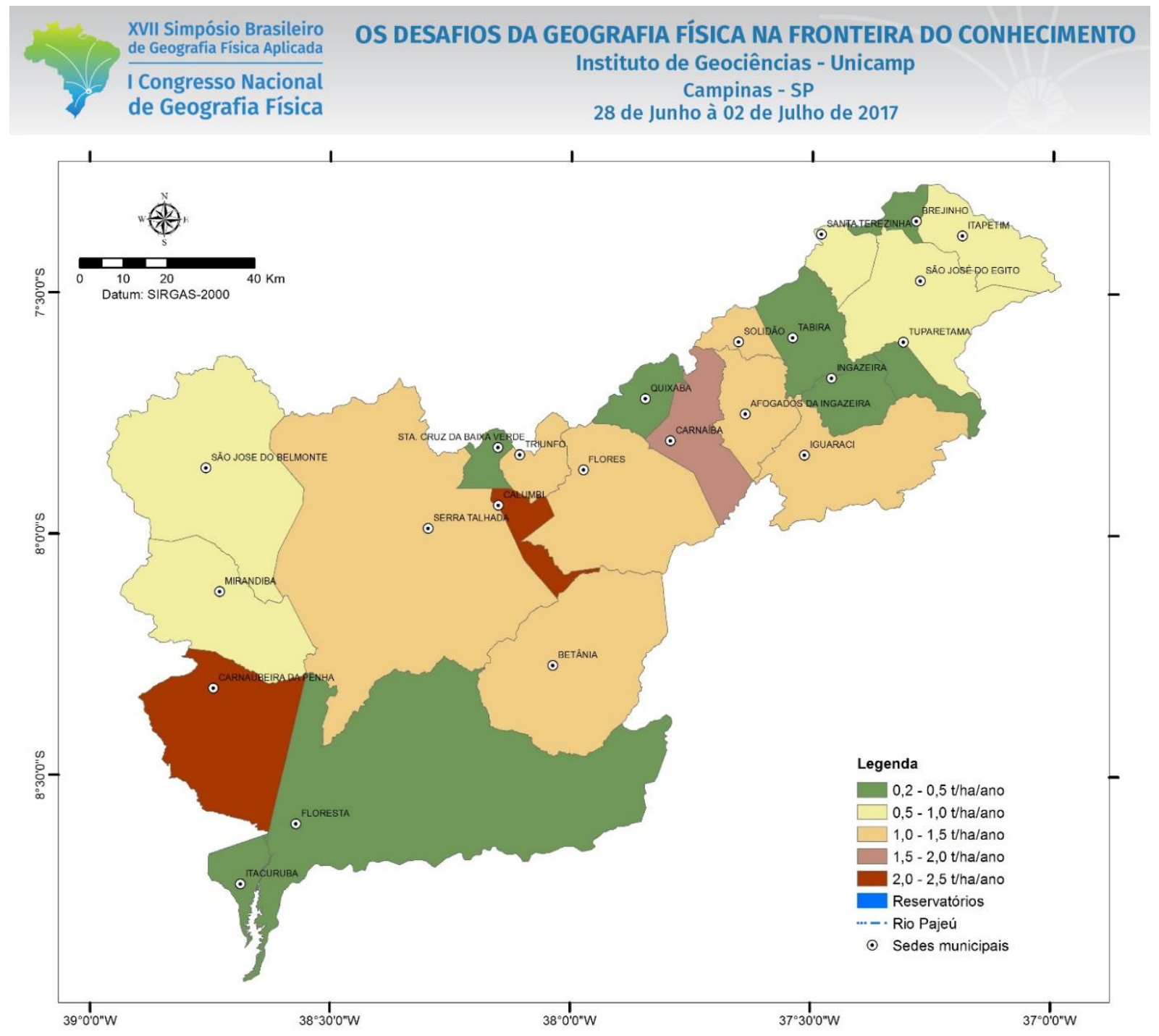

Figura 5 - Suscetibilidade à perda de solo por erosão hídrica na bacia do Pajeú

Os valores apresentados na Figura 6 se configuram como a média dos valores estimados para cada pixel no município. Há, portanto, diferenças internas nos municípios em função da existência de áreas serranas e de outros aspectos ambientais locais. Não obstante, optou-se por calcular a média municipal com o intuito do mapa servir de base para o planejamento de ações de combate à desertificação.

Mesmo as médias municipais de perda de solo anual por hectare tendo apresentado valores relativamente pequenos, quando se contabiliza o total municipal pode-se observar a gravidade do fato. Por exemplo, tomando-se como referência o município de Floresta, que apresentou uma média de 0,46 t/ha/ano, e sabendo-se que o trecho deste município pertencente à bacia tem 294.179 ha, pode-se estimar que neste município anualmente há uma perda superior a 135.000 t de solo por erosão hídrica neste município.

A média total estimada para a bacia do Pajeú foi de 0,97 t/ha/ano, o que implica numa estimativa de perda anual de 1.644.261 toneladas de solo por erosão hídrica. Uma parcela significativa deste solo erodido é 
retirada do horizonte superficial do solo, o que propicia a perda da fertilidade natural e, consequentemente, reduz sua capacidade de produção agrícola.

Alguns resultados alcançados em outros estudos no semiárido brasileiro mostraram similaridade aos aqui apontados. Em estudo realizado na própria bacia do Pajeú Ferreira et al. (2014) estimou a erosividade das chuvas entre 2.307 e $6.234 \mathrm{MJ} . \mathrm{mm} / \mathrm{ha}$.h.ano.

Aquino et al. (2006) estimaram que a erosividade das chuvas nas terras secas do Estado do Piauí varia de 3.316 a 6.877 MJ.mm/ha.h.ano, valores muito próximos dos encontrados no presente trabalho. Para o semiárido Pernambucano, Cantalice et al. (2009) identificaram as linhas isoerosivas - como são chamadas as isolinhas de erosividade das chuvas - de 2.000 a $5.000 \mathrm{MJ} . \mathrm{mm} / \mathrm{ha} . \mathrm{h}$. ano, valores semelhantes aos encontrados por Oliveira, Wendland e Nearing (2012), que identificaram valores de erosividade das chuvas entre 1.672 e 6.000 MJ.mm/ha.h.ano na região semiárida do Nordeste do Brasil.

No município de Sumé, Paraíba, Francisco et al. (2014) identificaram valores de erodibilidade dos solos entre 0,01 e 0,04 t.ha.h/ha.MJ.mm. Na região do Agreste Pernambucano, Campos Filho et al. (1992) estimaram a erodibilidade em 0,013 t.ha.h/ha.MJ.mm.

Também no município de Sumé, na Paraíba, Albuquerque et al. (2004) encontraram a erosividade média das chuvas de 4.928 MJ.mm/ha.h.ano e a erodibilidade dos solos de 0,013 t.ha.h/ha.MJ.mm.

\section{Conclusões}

Foi estimada uma perda média de solo por erosão hídrica entre 0,2 e 2,5 t/ha/ano para os diferentes municípios da bacia. A perda média estimada para o conjunto das terras da bacia hidrográfica do Rio Pajeú foi de 0,97 t/ha/ano, o que se traduz em uma suscetibilidade de perda anual de 1.644.261 toneladas de solo por erosão hídrica na bacia.

Com a realização deste trabalho espera-se contribuir para as ações de planejamento e combate à desertificação na região estudada.

\section{Bibliografia}

ABRAHAM, E. M. Indicadores de desertificación para Argentina, Bolivia, Brasil, Chile, Ecuador y Perú. In: ABRAHAM, E. M.; BEEKMAN, G. B. Indicadores de la Desertificación para América del Sur. MendozaArgentina: LaDyOt-IADIZA-CONICET, 2006.

ADEDIJI, A.; TUKUR, A. M.; ADEPOJU, K. A. Assessment of Revised Universal Soil Loss Equation (RUSLE) in Katsina Area, Katsina State of Nigeria using Remote Sensing (RS) and Geographic Information System (GIS). Iranica Journal of Energy \& Environment, v. 1, n.3, p. 255-264, 2010. 
ALBUQUERQUE, E. M.; et al. Análise do comportamento do NDVI e NDWI sob diferentes intensidades pluviométricas no município de Sousa-PB. Revista Estudos Geoambientais, Rio Tinto, n. 01, v. 01; Jan-Abr, 2014.

AQUINO, C. M. S.; OLIVEIRA, J. G. B.; SALES, M. C. L. Estimativa da erosividade das chuvas (R) nas terras secas do Estado do Piauí. Revista Ciência Agronômica, v. 37, n. 3, p.287-291, 2006.

BERTONI, J.; LOMBARDI NETO, F. Conservação do solo. 8. ed. São Paulo: Ícone, 2012.

BOUYOUCOS, G. W. The clay ratio as a criterion as susceptibility of soils to erosion. J. Amer. Soci. Agron., Madison, Wisc., 27, p. 738-741, 1935.

CAMPOS FILHO, O. R.; SILVA, I. F.; ANDRADE, A. P.; LEPRUN, J. C. Erosividade da chuva e erodibilidade do solo no Agreste de Pernambuco. Pesq. agropec. bras., v. 27, n. 9, p.1369-1370, 1992.

CANTALICE, J. R. B. et al. Linhas Isoerosivas do Estado de Pernambuco - $1^{\text {a }}$ aproximação. Revista Caatinga. v. 22, n. 2, p.75-80, 2009.

CASTRO, W. J. et al. Erodibilidade de Solos do Cerrado Goiano. Revista em Agronegócios e Meio Ambiente, Maringá, v. 4, n. 2, p. 305-320, 2011.

EMBRAPA SOLOS. Sistema de Informações de Solos Brasileiros. Disponível em: < http://www.bdsolos.cnptia.embrapa.br/consulta_publica.html> Acesso em: 15 jul. 2015.

FARHAN, Y.; ZREGAT, D.; FARHAN, I. Spatial Estimation of Soil Erosion Risk Using RUSLE Approach, RS, and GIS Techniques: A Case Study of Kufranja Watershed, Northern Jordan. Journal of Water Resource and Protection, v. 5, p. 1247-1261, 2013.

FERREIRA, P. S. et al. Análise do cenário de suscetibilidade à desertificação na bacia hidrográfica do rio Pajeú Estado de Pernambuco. Scientia Plena, v. 10, n. 10, p. 1-11, 2014.

FRANCISCO, P. R. M.; RIBEIRO, G. N.; MORAES NETO, J. M. Mapeamento da Deterioração Ambiental em Área de Vegetação de Caatinga. Revista Brasileira de Geografia Física v. 07, n. 02, p.304-318, 2014.

GALETI, P. A. Conservação do solo: reflorestamento e clima. Campinas, Instituto Campineiro de ensino agrícola, 257p. 1982.

GUERRA, A. T; GUERRA, A. J. T. Novo dicionário geológico-geomorfológico. 3.ed. Rio de Janeiro: Bertrand Brasil, 2003.

HUDSON, N., Conservacion del suelo. Barcelona: Reverté,1982.

LEPSCH, I. F. Formação e Conservação dos Solos. São Paulo: Oficina de Textos, 2002.

LOMBARDI NETO, F.; MODENHAUER, W. C. Erosividade da chuva: sua distribuição e relação com as perdas de solo em Campinas (SP). Bragantia, Campinas, 51 (2), p. 189-196, 1992.

MANNIGEL, A. R. et al. Fator erodibilidade e tolerância de perda dos solos do Estado de São Paulo. Acta Scientiarum, Maringá, v. 24, n. 5, p. 1335-1340, 2002.

MARQUES, V. S. Erosão hídrica em microbacia utilizando geotecnologias. Tese (doutorado), Universidade Federal Rural do Rio de Janeiro, Curso de Pós-Graduação em Agronomia. Seropédica, 2013.

MIRANDA, E. E. (Coord.). Brasil em Relevo. Campinas: Embrapa Monitoramento por Satélite, 2005. Disponível em: 〈http://www.relevobr.cnpm.embrapa.br〉. Acesso em: 26 jun. 2015.

OLIVEIRA, P. T. S.; WENDLAND, E.; NEARING, M. A. Rainfall erosivity in Brazil: A review. Catena, v. 100, p.139-147, 2012.

PERNAMBUCO. Atlas de bacias hidrográficas de Pernambuco. Recife: Secretaria de Ciência, Tecnologia e Meio Ambiente, 2006.

PERNAMBUCO. Plano estadual de recursos hídricos. Recife: Secretaria de Ciências, Tecnologia e Meio Ambiente, 1998. 
PULIDO GÓMEZ, J. D. Estimativa de erosão pela Equação Universal da Perda de Solo (USLE) e transferência de sedimentos para todo território brasileiro. Dissertação (Mestrado), Escola Superior de Agricultura. 89 p. Piracicaba, 2012.

RENARD, K. G.; et al. Predicting Soil Erosion by Water: A Guide to Conservation, Planning with the Revised Universal Soil Loss Equation (RUSLE). Washington: USDA/ARS - Agriculture Handbook n. 703, 1997.

SHARP, R. et al. InVEST 3.2.0 User's Guide. The Natural Capital Project, Stanford

University, University of Minnesota, The Nature Conservancy, and World Wildlife Fund, 2015. Disponível em: <http://www.naturalcapitalproject.org/invest/>. Acesso em: 03 Nov. 2015.

WISCHMEIER, W. H. \& SMITH, D. D. Predicting rainfall erosion losses: a guide to conservation planniing. Washington, USDA, 1978. 58 p. (Agricultural Handbook, 537). 